\title{
Analysis of Real Estate Tax System Reformation in China
}

\author{
Binfan Tian a, Yongzhong Tang ${ }^{b}$
}

School of Economics and Management, Beijing Jiaotong University, Beijing 100044, China

a14120655@bjtu.edu.cn, byzhtang@bjtu.edu.cn

\begin{abstract}
In recent years, the demand of houses is booming, making the house price increase sharply. Tax is a "visible hand" of government in regulating economy, that the allocation of marketing resources can be optimized to improve the social welfare, by reforming the tax system reasonably. Based on the theory of equilibrium, this paper analyzes the effect of turnover tax reduction and property tax levy on housing price. Then, from the perspective of game theory, it makes analysis about how will they act if the central government rewards local governments incentively for reforming the tax system, What's more, it also analyzes how the equilibrium solution of game interprets the principal-agent relationship between central government and local governments. At last, this paper puts forward reasonable suggestions accordingly.
\end{abstract}

Keywords: real estate tax; turnover tax; property tax; game theory.

\section{中国房地产税制结构改革分析}

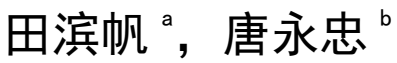

\section{北京交通大学，经济管理学院，北京 中国}

a14120655@bjtu.edu.cn, byzhtang@bjtu.edu.cn

摘 要: 近年来, 旺盛的购房需求拉动了我国房价的大幅上涨。税收是政府调控经济的一只 “看 得见的手”, 通过对税制结构的合理改革, 可以对市场资源进行优化配置, 提高全社会福利。 本文从均衡理论出发, 分析降低流转税并开征房产税对房价产生的影响, 然后从博弯论的角 度, 分析如果中央政府对地方政府实施税制改革的行为实行激励性奖励, 双方将会如何行动, 博栾的均衡解如何阐释中央政府与地方政府之间的委托代理关系, 最后据此提出合理的建议。

关键词: 房地产税; 流转税; 房产税; 博弯论

\section{1. 前言}

2015 年 3 月 1 日, 《不动产登记暂行条例》正式实施。“条例” 提出, 未来各级不动产 信息将统一纳入国土部牵头建立的不动产登记信息管理平台, 并确保国家、省、市、县四级 登记信息实时共享。

2016 年 1 月 6 日，国务院总理李克强在国务院常务会议上指出，“督查要建立奖惩并举 机制, 结合 ‘干部能上能下' 制度, 要让多干事、能干事、愿干事的干部 “上” 来, 激发各地 竞相推动科学发展。”自 2015 年年中以来, 国务院持续通过督查推动重大决策部署和政策措 施落实，对中央政策落实得力的地方给予资金政策等奖励 ${ }^{[1]}$ 。

这客观上将成为未来合理设计房地产税制的决策支持和实施征管的运行保障条件。

根据生产经营流通环节不同，房地产各环节涉及的税收主要有：营业税、企业所得税、 个人所得税、耕地占用税、契税、土地增值税、印花税、房产税、城市房地产税和城镇土地 使用税，共十个税种 (见表 1)。 
表1 按征税环节划分的房地产税收

\begin{tabular}{cc}
\hline 课税环节 & 涉及税种 \\
\hline 土地使用权出让环节 & 土地二级市场: 营业税及附加税、市业所得税、个人所得税、土地增值税、印花税、契税 \\
房地产开发环节 & 营业税及附加税、印花税 \\
房地产转让环节 & 营业税及附加税、企业所得税、个人所得税、土地增值税、印花税、契税 \\
房地产保有环节 & 房产税、城镇土地使用税 \\
\hline
\end{tabular}

我国现行房地产税比重占到房价的近 $1 / 4$, 且税负结构不均匀, 以流转税为主, 并远高于 保有环节的税负。房地产保有环节主要包括两个税种：房产税和城镇土地使用税。城镇土地 使用税当中, 个人所有的居住房屋及院落用地由省、自治区、直辖市地方税务局确定减免。 房产保有环节税负的相对较轻, 助长了投机性购房的发生, 导致了 “房哥” “房姐”一人便 拥有几十套空置住房, 而普通打工者们几十人挤一套合租房的怪现象。截至 2014 年, 全国的 房屋空置率已达到 $22.4 \%$, 而在北上广等一线城市, 部分小区的空置率甚至高达 $50 \%$ 。

针对这个问题, 国内有关学者分析, 国外重视对房地产保有的征税, 而房地产产权转让 的税收则相对较少 ${ }^{[3]}$ 。对保有环节征税, 将抑制消费者的购房需求, 减少市场对于房地产的需 求量，进而在一定程度上影响房地产企业投资的积极性，不过有利于房价的稳定 ${ }^{[4]}$ 。

因此，我国住房市场的税收制度改革立足于结构性的调整，通过将个人住房纳入房产税 的征税对象, 增加保有环节税收负担的比重, 适度降低开发和交易环节的税收负担, 以期调 节房地产市场的住房价格。在市场经济的环境下, 旺盛的购房需求会拉动房价的大幅上涨, 税收是政府调节经济的一只 “看得见的手” ，降低流转环节的税负并增加保有环节的税负， 将会对房价产生怎么样的影响?

本文将从均衡理论出发, 分析税收制度的合理改革将会对市场需求产生的影响, 然后从 博亦论的角度出发, 分析中央政府与地方政府针对该改革应采取的不同策略, 最后提出建议。

\section{2. 房地产税制结构改革}

2.1. 降低流转税

我国现行的房地产相关税种, 多设置于房地产的交易环节, 而保有环节的税收很少, 导 致房地产税收具有明显的 “一次性” 特征。从土地使用权的取得到商品房的最终销售使用涉 及房地产的开发环节、销售环节和使用环节, 每一个环节都涵盖相应的税种和税目。在近两 年房地产各相关环节税收中, 房地产的销售环节对地方税收收人的贡献最大, 地位最为重要 （见表 2）。

表2 房地产相关税种收入情况

\begin{tabular}{ccc}
\hline 税种 & 2014年（亿元） & 2103年（亿元） \\
\hline 契税 & 4000.70 & 3844.02 \\
耕地占用税 & 2059.05 & 1808.23 \\
土地增值税 & 3914.68 & 3293.91 \\
房地产开发企业主营业务税金及附加 & 5968.43 & 6204.18 \\
城镇土地使用税 & 1992.62 & 1718.77 \\
房产税 & 1851.64 & 1581.50 \\
数据来源: 国家统计局http://ww. stats. gov. cn/ &
\end{tabular}

根据科斯的交易成本理论, 高交易成本会妨碍市场的有效率运行。现行房地产税收制度 中流转税过高，无疑会提高交易成本，影响市场效率。 


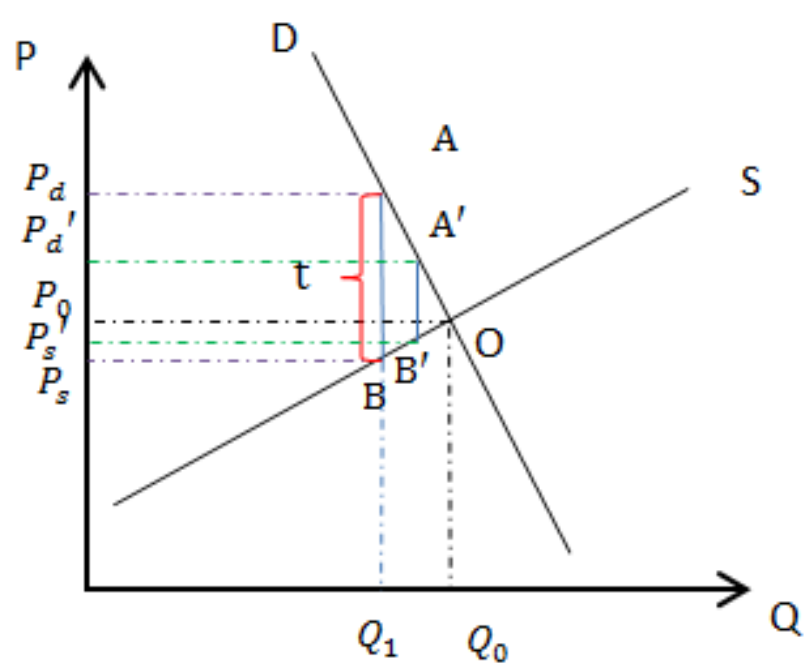

图1 房地产流转税对市场的影响

如图1所示, $\mathrm{D}$ 代表消费者的购房需求曲线, $\mathrm{S}$ 代表房屋的供给曲线(包括新房和二手房)。 房地产市场原本在 $\mathrm{O}$ 点达到了均衡, 此时均衡价格是 $P_{0}$, 均衡数量是 $Q_{0}$ 。在政府征收了 $\mathrm{t}=P_{d}-$ $P_{S}$ 的税收后, 均衡数量减少到了 $Q_{1}$, 消费者的购买价格上升到了 $P_{d}$, 生产者的售卖价格降低 到了 $P_{S}$ 。

由于房屋的替代品很少, 且大多数中国人的观念是买房住, 租房只是解决一时之需, 这 导致房地产的需求弹性小, 在一线城市更是刚性需求, 所以曲线 $\mathrm{D}$ 很陡峭; 而房屋的供给弹性 却较大, 因为房产持有者在现行的税收制度下, 保有房屋的费用很低, 完全可以等房价上涨 后再出手, 所以曲线 $S$ 较平缓。当下房屋买卖交易, 流转税一般也是由购房者承担。这样就导 致了房地产流转税在很大程度上把税负转嫁给了房地产需求者, 给其带来了梯形 $\mathrm{A} P_{d} P_{0} O$ 的损 失; 但只给房地产供给者带来梯形 $O P_{0} P_{S} B$ 的损失。政府在得到了矩形 $A P_{d} P_{s} B$ 的税收后, 全社 会的福利损失是三角形 $\mathrm{ABO}$ 。

如果降低流转税到 $\mathrm{t}^{\prime}=P_{d}{ }^{\prime}-P_{s}{ }^{\prime}$, 房地产需求者获益最大, 消费者剩余增加了梯形 $\mathrm{A} P_{d} P_{d}{ }^{\prime} A^{\prime}$; 房地产持有者的生产者剩余只增加了梯形 $\mathrm{B} P_{S} P_{s}{ }^{\prime} B^{\prime}$, 但社会总福利增加了梯形 $\mathrm{ABB}^{\prime} A^{\prime}$ 。所以，降低流转税更有利于发挥市场的资源配置效率。

\section{2. 开征房产税}

在世界各国的国民经济活动中，房地产业具有举足轻重的地位，对房地产开发、经营、 使用和转让等活动进行征税, 构成了世界各国和地区房地产税制的重要内容。尽管房产税的 征税形式多种多样，但其目的都是为了增加地方财政收入，增强地方政府提供基本公共服务 的能力。目前大部分国家都对保有环节的房地产征税。

英国与房地产相关的主要税种是房地产保有环节的住宅房屋税, 住宅房屋税属于地方税, 按照房产的评估价值征收, 税率由各地方政府制定, 实行地区差别幅度定额税率。在房地产 保有环节, 对所有房屋, 包括住宅房屋与非住宅房屋征税, 其中对居住用房屋, 按应税财产 的评估价值征收住房财产税，对非住宅用房屋，按照租金征收营业房屋税。

美国在房地产保有环节针对土地和房屋合并的财产, 按应税财产的评估价值, 征收财产 税。保有环节的财产税属于地方税, 税率也一般由地方政府每年确定一次。保有环节的财产 税是美国地方政府财政收入的主要来源，同时也是平衡地方财政预算的重要手段。

德国房地产相关的主要税种有：土地税、房产税、土地交易税和资本利得税。德国的土 地税是对农业生产用地和建筑用地征税, 其中农业生产用地按其产出价值征税, 而建筑用地 则按评估价值征税。德国的土地税属于地方税, 主要由地方支配, 是市镇地方财政收人的一 个重要组成部分。 
房产税作为一种保有税是地方政府主要的税收来源, 而且是较为稳定的税源, 但我国并 未开征房产税。对于房产税的课税对象, 学界普遍认为, 应该对高档房 ${ }^{[5]}$ 、超出人均免税面积 部分和多套房产 ${ }^{[6]}$ 的所有者进行征税。

如图2所示, 在开征房产税之前, 房地产市场在 $\mathrm{O}$ 点达到均衡, 均衡价格是 $\mathrm{P}$, 均衡数量 是 $\mathrm{Q}_{0}$ 。政府开征房产税, 由于这种保有税类似于物业费, 在获得房屋所有权以后, 每年都要 缴税。对于购买第一套房或者人均面积未超出免试范围的购房需求者, 是免征房产税的, 这 样, 这部分的需求就不会变化。但对于投机性需求, 在得到房屋所有权后, 就必须每年缴纳 保有税, 这样会影响他们的预期收益, 从而抑制一部分投机性购买, 所以, 需求曲线小幅左 移到曲线D'处。

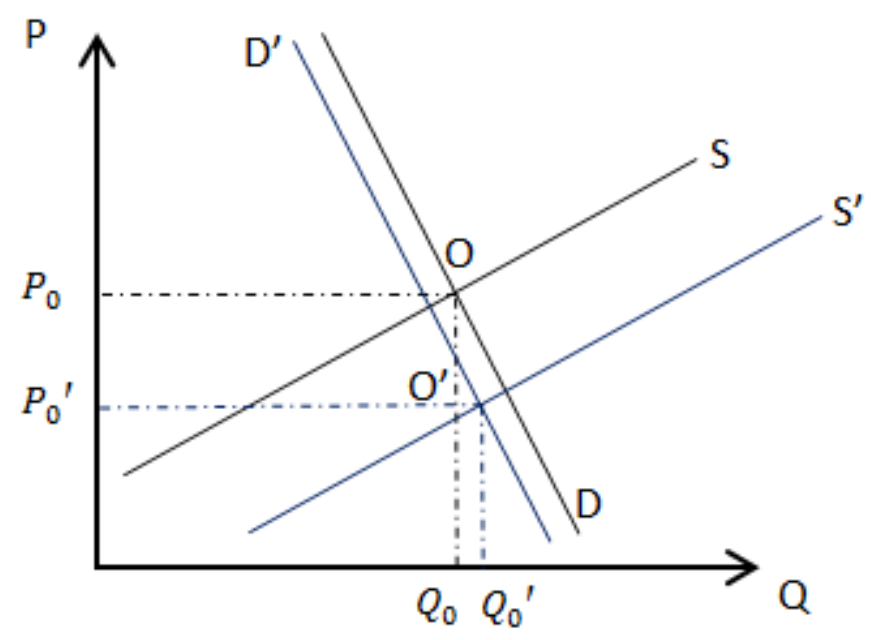

\section{2 房地产保有税对市场的影响}

房地产供给方也会由于房产税的图开征，增加了房屋持有的成本，预期收益会下降，会 激发原来的空置房转入交易市场。故供给曲线会较大幅度地右移到曲线 S'处。新的均衡点是 $\mathrm{O}^{\prime}$, 房价会从原来的 $P_{0}$ 下降到 $P_{0}{ }^{\prime}$, 由于打击了房屋市场的投机性交易, 房价下降, 更多自住 型购房需求得到了满足, 房屋空置率下降, 市场资源得到了更有效的配置。

\section{3. 税制改革的实施}

近年来, 中央政府一直在控制房价的过快增长, 但是往往收效甚微。中央政府的目标是 通过税制改革的实施来合理控制房价, 以使全社会福利最大化; 其税制改革的政策一般由地 方政府执行, 所以, 中央政府是委托人, 地方政府是代理人。假设中央政府是风险中性的, 地方政府是风险规避的, 二者都是理性的; 信息是不对称的, 地方政府贯彻中央税制改革政 策的努力程度只有自己知道, 中央政府不知道, 但二者都知道, 房价的控制程度 $f(d)$ 与地方 政府的努力程度 $d$ 是呈正比的，假设两者呈线性关系: $f(d)=d+\mu, \mu$ 代表外生的不确定因 素, 且 $\mu \sim \mathrm{N}(0, \sigma)$, 即 $\mu$ 服从均值为 0 , 方差为 $\sigma^{2}$ 的正态分布, 则 $\mathrm{E}[f(d)]=d, \mathrm{D}[f(d)]=\sigma^{2}$ 。 中央政府根据地方对房价的控制程度 $f(d)$ 进行奖励, 奖励 $a(f)$ 与控制程度 $f(d)$ 呈线性正 相关: $a(f)=\beta f(d), 0<\beta<1, \beta$ 越大, 对地方政府的激励越大。

设中央政府的效用函数是 $u_{1}(\beta)=f(d)-a(f)=(1-\beta) f(d)$, 其期望效用为:

$E\left[u_{1}(\beta)\right]=(1-\beta) E[f(d)]=(1-\beta) d$

而房地产税本质上是地方政府收益税，进行税制改革会使房价下降，从而减少地方政府 的收益。假设地方政府进行税制改革的努力程度 $d$ 与由于房价下降导致地方政府收益的减少量 $l(d)$ 呈正相关: $l(d)=\gamma d^{2} / 2, \gamma>0, \gamma$ 越大，地方政府努力的成本越大。地方政府的收益 $R(d)=a(f)-l(d)=\beta f(d)-\gamma d^{2} / 2$, 期望收益为:

$E[R(d)]=\beta E[f(d)]-\gamma d^{2} / 2=\beta d-\gamma d^{2} / 2$ 

恶系数:

由于地方政府是厌恶风险的，设其效用函数为 $u_{2}(R)=-e^{-\rho R(d)}$, 地方政府的绝对风险厌

$$
A(R)=-u_{2}^{\prime \prime} / u_{2}^{\prime}=\rho^{2} e^{-\rho R} / \rho e^{-\rho R}=\rho
$$

因为地方政府厌恶风险，所以 $\rho>0 ， \rho$ 越大，代表其对风险的厌恶程度越高。地方政府 的期望效用为:

$$
\begin{aligned}
E\left[u_{2}(R)\right]=-E\left[e^{-\rho R(d)}\right] & =-E\left[e^{-\rho\left(\beta(d+\mu)-\gamma d^{2} / 2\right)}\right] \\
& =-e^{-\rho\left(\beta d-\gamma d^{2} / 2\right)} \int_{-\infty}^{+\infty} e^{-\rho \beta \mu} d F(\mu) \\
& =-e^{-\rho\left(\beta d-\gamma d^{2} / 2\right)} \int_{-\infty}^{+\infty} e^{-\rho \beta \mu} \cdot \frac{1}{\sqrt{2 \pi} \sigma} e^{-\frac{\mu^{2}}{2 \sigma^{2}}} d \mu \\
& =-e^{-\rho\left(\beta d-\gamma d^{2} / 2\right)} \cdot e^{\frac{\rho^{2} \beta^{2} \sigma^{2}}{2}} \int_{-\infty}^{+\infty} \frac{1}{\sqrt{2 \pi} \sigma} e^{-\frac{\left(\mu+\rho \beta \sigma^{2}\right)^{2}}{2 \sigma^{2}}} d \mu \\
& =-e^{-\rho\left(\beta d-\gamma d^{2} / 2-\rho \beta^{2} \sigma^{2} / 2\right)}
\end{aligned}
$$

其中, $F(\mu)$ 是 $\mu$ 的分布函数。假设地方政府的保留收益为 $R_{0}$, 那么, 代理人的参与约束条 件是:

$$
-e^{-\rho\left(\beta d-\gamma d^{2} / 2-\rho \beta^{2} \sigma^{2} / 2\right)} \geq-e^{-\rho R_{0}}
$$

即

$\beta d-\gamma d^{2} / 2-\rho \beta^{2} \sigma^{2} / 2 \geq R_{0}$

作为理性经济人，地方政府会根据自身条件和中央政府的激励情况，选择最合适的努力 程度 $d$, 使自身期望收益最大化:

$\max _{d} E[R(d)]=\beta d-\gamma d^{2} / 2$

一阶条件:

$d=\beta / \gamma$

中央政府则需要选择合适的激励力度, 使自身期望效用最大化:

$\max _{\beta} E\left[u_{1}(\beta)\right]=(1-\beta) d$

由地方政府的代理人参与条件, 有 $\beta d \geq R_{0}+\gamma d^{2} / 2+\rho \beta^{2} \sigma^{2} / 2$, 又由地方政府收益最大 化的一阶条件，有 $d=\beta / \gamma$, 代入中央政府的期望效用函数中，有

$E\left[u_{1}(\beta)\right]=\beta / \gamma-R_{0}-\gamma(\beta / \gamma)^{2} / 2-\rho \beta^{2} \sigma^{2} / 2$

一阶条件:

$\beta=1 /\left(1+\gamma \rho \sigma^{2}\right)$

最终, 地方政府会选择努力程度 $d=1 / \gamma\left(1+\gamma \rho \sigma^{2}\right)$, 预期最大收益为

$E[R(d)]=\beta d-\gamma d^{2} / 2=R_{0}+\rho \sigma^{2} / 2\left(1+\gamma \rho \sigma^{2}\right)^{2}$

中央政府的预期最大效用为:

$E u_{1}(\beta)=(1-\beta) d=1 /\left[2 \gamma\left(1+\gamma \rho \sigma^{2}\right)\right]-R_{0}$

从上述结果, 可以推知, $\gamma 、 \rho$ 和 $\sigma^{2}$ 越大, $\beta$ 和 $d$ 越小, 意味着地方政府努力的成本 $\gamma$ 越高, 其对风险的厌恶程度 $\rho$ 越高, 外生不确定性因素的方差 $\sigma^{2}$ 越大, 中央政府愿意给予地方政府的 激励性奖励就越少, 地方政府选择的努力程度也就越低, 但与此同时, 地方政府的风险也会 减少。这是因为, 一旦地方政府的努力成本过高, 中央政府的奖励可能无法对其产生激励效 应, 所以, 干脆减少奖励甚至不奖励; 地方政府对风险的厌恶程度越高, 由外生不确定性因 素导致的方差越大, 而激励性奖励是不确定性收益, 会致使地方政府宁愿选择较低的努力程 度, 得到较少的激励性奖励, 也要尽可能地回避风险。

所以，要增加地方政府贯彻税制改革政策的努力程度，就应该给予地方政府一个相对稳 定的外部环境, 比如在可预见的未来, 中央承诺的奖励能切实得到兄现, 可以减少地方政府 对房价控制程度的方差 $\sigma^{2}$, 减少不确定性对风险规避型地方政府带来的影响; 也可以把减弱 GDP在地方政绩考核的重要性, 因为如果地方政府积极响应中央政策, 将会由于房价的下降, 影响GDP的增长，这样就可以减少地方政府努力的成本 $\gamma$ 。 


\section{4. 结论}

综上所述，降低流转环节的税负并增加保有环节的税负，会降低房价，增加购买第一套 房或者人均面积未超出免税范围的购房需求者的福利, 对于投机性购买有一定的抑制作用, 有利于促进市场交易，减少房屋空置率，能够促进整个社会资源配置效率的提高。

在分税制的体制下，中央政府和地方政府的利益并不一致的，二者在实施税制改革政策 方面存在委托一代理关系。要使房地产税制改革得到地方政府的切实执行，中央政府可以通过 提高对地方政府执行政策的奖励，来提高地方政府执行中央政策的积极性; 并通过树立公信 力, 来降低不确定性对地方政府努力程度的负面影响; 弱化GDP在地方政绩考核的重要性, 加 强调控房价在考核中的重要性，来消除地方政府对新政策的抵触心理。

\section{References}

[1] Information on: http://www.jinghua.cn/404.shtml

[2] Yupei Zhang, Jinqiu Peng, Yu Liu. Feasibility analysis on the impact of China's real estate tax on property prices. China Collective Economy. Vol.40 (2015) No. 03, p. 73-74.

[3] Gang Liu. The reform and suggestion of the real estate tax policy. Northern Economy and Trade . Vol. 35 (2015) No. 02, p. 64-65.

[4] Liqin $\mathrm{Xu}$. Real estate tax reform's impact on the real estate market players. Modern Economic Information. Vol. 188 (2015) No. 01, p. 237.

[5] Mingxun Liu, Huimin Hu. "Tobin tax" will give some enlightenment to our country's real estate transaction tax. Public Finance Research. Vol. 32(2011) No. 08, p. 12-14.

[6] Tian Tian, Weican Fu. A tax on owners of multiple properties is the most effective measures in regulating the real estate supply and demand. Journal of Hunan Tax College. Vol. 26 (2013) No. 03, p. 13-31. 